\title{
Crosslinking of Starch Xanthate. V. Redox Grafting with Hydrogen Peroxide and Vinyl Monomers in Water*
}

\author{
George G. MAHER \\ Northern Regional Research Center, Federal Research, \\ Science and Education Administration, U.S. Department of Agriculture, \\ Peoria, Illinois 61604, USA.
}

(Received November 29, 1977)

\begin{abstract}
Soluble starch xanthate (SX) with a degree of substitution (D. S.) ranging from 0.09 to 0.56 reacted with vinyl monomers (acrolein, acrylamide, acrylic acid, acrylonitrile, methyl acrylate, or styrene) and hydrogen peroxide to form aqueous gels of crosslinked starchpoly(vinyl monomer) graft copolymer. The reaction progress was followed by viscometry while investigating the effects of varied D.S. and monomer and peroxide levels. Solids, precipitated from the gels by ethanol, were analyzed for nitrogen and sulfur and their compositions were calculated. The vinyl monomer polymerization ranged from 30 to $98 \%$ in the grafting. A residual sulfur content was equivalent to a remainder xanthate D. S. of 0.04 to 0.24. Infrared absorption spectra verified copolymer formations and indicated that homopolymer formation was minimal.
\end{abstract}

KEY WORDS Starch Xanthate / Vinyl Monomers / Graft Copolymer / Hydrogen Peroxide / Aqueous Redox /

Recent reports have concerned the grafting reaction of vinyl monomers with xanthates (dithiocarbonate derivatives of alcohols) of polysaccharides, cellulose, ${ }^{1}$ and starch, ${ }^{2}$ in the presence of hydrogen peroxide. Since the initiation of the work reported here, a grafting of a starch thiol derivative with vinyl monomer has been accomplished. $^{3}$ In all of these works, the reaction has been in a heterogeneous system, the polysaccharide derivatives have been insoluble, and the hydrogen peroxide initiator-redox system has been at acidic $\mathrm{pH}$. In the last reference work, repeated alternating grafting reactions and sodium boronhydride treatments were made to get increased grafting. We have applied the polymerization reaction to the aqueous redox system of completely soluble starch xanthate-hydrogen peroxide at alkaline $\mathrm{pH}$ and have found that it forms gels of poly(vinyl monomer) (PVM) grafted starch, cross-linked in a self-generated, acidic medium. The only other known homogeneous grafting reactions of this nature have involved the reaction of soluble monomeric xanthates in neutral solvents

\footnotetext{
* For Part IV, see Staerke, 29, 335 (1977).
}

with vinyl monomers. ${ }^{4,5}$

\section{EXPERIMENTAL}

\section{Materials}

Acrolein, acrylamide, acrylic acid, and styrene were reagent grade and acrylonitrile and methyl acrylate were practical grade organic chemicals from Eastman Organic Chemicals, Distillation Products Industries, Rochester, New York. Hydrogen peroxide was reagent grade, $30-\%$ aqueous solution from Merck \& Co., Inc., Rahway, New Jersey, or J. T. Baker Chemical Co., Phillipsburg, New Jersey. These chemicals were used as received.

SX samples were prepared from commercial pearl corn starch (from CPC International, Inc., Argo, Illinois) and aqueous sodium hydroxide and carbon disulfide by either a continuous "KoKneader" process (a reaction in a continuous screw-type mixer-reactor) $)^{6,7}$ or a "Roto-Feed" operation (a reaction in a continuous centrifugalpump mixer-reactor). ${ }^{8}$ They were stored at $5^{\circ} \mathrm{C}$ as aqueous solutions of the sodium salt, $\mathrm{pH}$ 11.5. 


\section{G. G. MAHER}

Because SX decomposes somewhat significantly in D.S. after several weeks' storage under these conditions, the solutions were used before that time. All xanthate solutions were analyzed for starch by the cuprimetric Somogyi method and for xanthate groups by a differential, acid titration method. ${ }^{6,7}$ From these data, sodium starch xanthate (NaSX) content and D.S. were calculated based on the anhydroglucose unit (AGU).

\section{Preparation of PVM Grafted Starch}

The basic reaction recipe and procedure to which variations were made are as follows. A weighed amount ( $c a .15 \mathrm{~g}$ ) of NaSX solution of known concentration (from $c a .10$ to $14 \%$ ) was added to $50 \mathrm{ml}$ of water and dissolved. A mixture of pipetted volumes of acrylonitrile (AN) and the $30-\% \mathrm{H}_{2} \mathrm{O}_{2}$ was then stirred in rapidly. The total mixture was permitted to stand at room temperature in beakers covered with a watch glass. Reaction was rapid, and in $0.5-1 \mathrm{~h}$, the entire content of the beaker was a white gelatinous mass, with a subsequent tendency to coalesce and exude liquid. The reaction was exothermic and effervescent, more so with higher D. S. xanthate.

Variables in the above process were the vinyl monomer and the amounts of monomer, $\mathrm{H}_{2} \mathrm{O}_{2}$, dry weight $\mathrm{NaSX}$, and the D.S. of the NaSX. The amount of water was varied so as to keep a constant concentration of starch in the final mixtures. In some reactions the xanthate solution $\mathrm{pH}$ was adjusted with dilute $\mathrm{HCl}$ prior to adding the $\mathrm{AN}-\mathrm{H}_{2} \mathrm{O}_{2}$ mixture, and the volume of acid used was considered in the starch concentration control. In these controlled concentration mixtures, the viscosity was measured as reaction time progressed, using a Brookfield Model LVF Viscometer with a No. 4 spindle at $6 \mathrm{rpm}$ (Brookfield Engineering Laboratories, Inc., Stoughton, Massachusetts). Thus, viscosity measurements are repeatable with in $100 \mathrm{cP}$. An individual reaction mixture was used for each viscosity determination. The $\mathrm{pH}$ was determined at various times during the course of an 18-h reaction.

Solid material was isolated from the gels by stirring them gently in $200 \mathrm{~m} l$ of $95-\%$ ethanol in a Waring Blendor for a few minutes to yield a fine suspension, which was allowed to settle overnight and then decanted. The solids were washed with 95- \% ethanol in a 50-m $l$ centrifuge tube by stirring occasionally over a 1-hr period and then centrifuging. This procedure was repeated three times and then the solids were kept overnight in absolute ethanol. Following three similar washings with ethyl ether, the solids were dried to a constant weight in a vacuum desiccator over $\mathrm{P}_{2} \mathrm{O}_{5}$ at room temperature. The dry, cross-linked starch copolymer was analyzed for nitrogen content by a standard micro-Kjeldahl procedure. Sulfur was determined by White's Schöniger flask oxidationbarium perchlorate titration method. ${ }^{9}$ Infrared absorption spectra (IR) were obtained with Nujol mulls in a sodium chloride cell with a PerkinElmer Model 137 Infracord spectrophotometer.

A portion of cross-linked starch-polyacrylonitrile (PAN) copolymer (Run 12a) was subjected to extraction with dimethylformamide (DMF) in the process of Brockway and Seaberg. ${ }^{10}$ Centrifugation was used to separate liquid extract and solid residue. Extract and residue were each then put into ethanol, and the resulting solids were isolated and washed as above. IR of the dry products were obtained.

\section{RESULTS AND DISCUSSION}

\section{$S X, A N$, Hydrogen Peroxide Reaction}

The reaction is a seemingly complex one, as is evident even in the simple measurements and evaluations of reaction-media viscosities shown in Figures 1-3. Inflections are noted in some of the time versus viscosity plots. No explanation is attempted for this phenomenon, although patterns to the inflection appearances are noted in run series. The plots were single-point plots, not averaged replicates; nevertheless, the smooth progressive changes in viscosity as variables were observed in the reactions of the run series stand out clearly. A similar situation was observed in a $\mathrm{SX}$-polyacrolein reaction, ${ }^{11}$ wherein complete bar plots showed the repeatability of the run-series curves. Within the limits studied, one can attempt some generalization in regard to the viscosity developments. For a given D.S. and amount of $\mathrm{H}_{2} \mathrm{O}_{2}$, an increase in the amount of AN used increases the initial rate and the maximum and final viscosities. attained as shown in Figure 1a, but in Figure 2a, Run 12, and in Figure 3a, Run 18 are anomalous to such a deduction. At a given D. S. and amount of $\mathrm{AN}$, an increase in the amount of $\mathrm{H}_{2} \mathrm{O}_{2}$ used may 


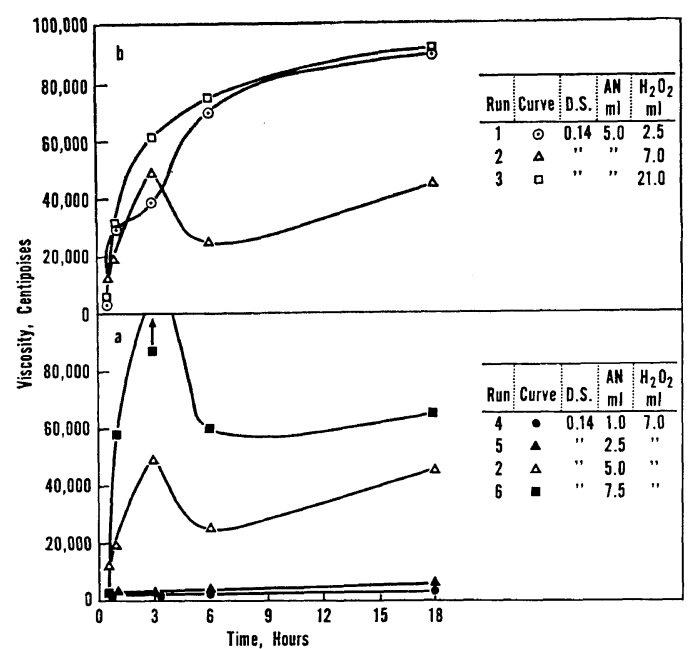

Figure 1. Viscosity development in 0.14 D.S. starch xanthate-hydrogen peroxide-acrylonitrile reactions. The arrow sign signifies that at this time point, the viscosity was somewhere in excess of 100,000 centipoises, which is the maximum viscosity that the instrument used could measure.

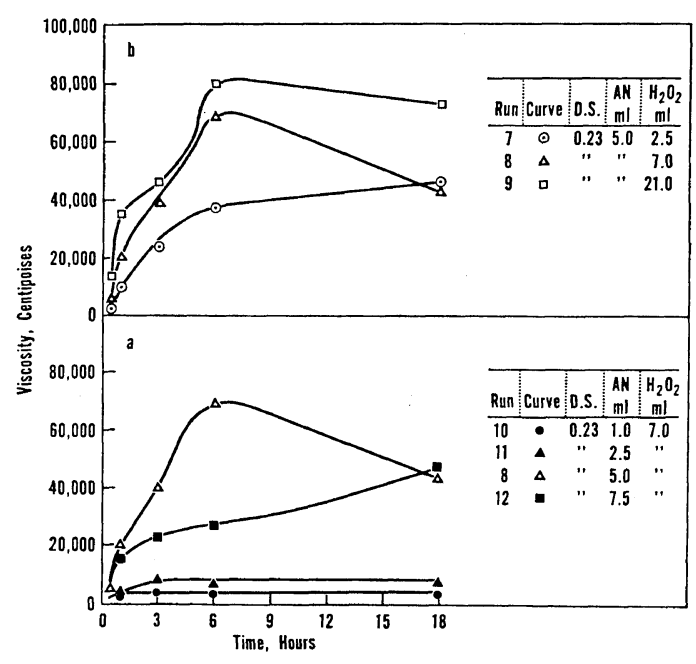

Figure 2. Viscosity development in 0.23 D. S. starch xanthate-hydrogen peroxide-acrylonitrile reactions.

increase the initial rate and maximum viscosities, but not necessarily the final viscosity reached. With a given mixture of $\mathrm{AN}$ and $\mathrm{H}_{2} \mathrm{O}_{2}$, increasing the xanthate D.S. shows that an intermediate D.S. may produce a lag in the initial rate and in the maximum and final viscosities gained, depending

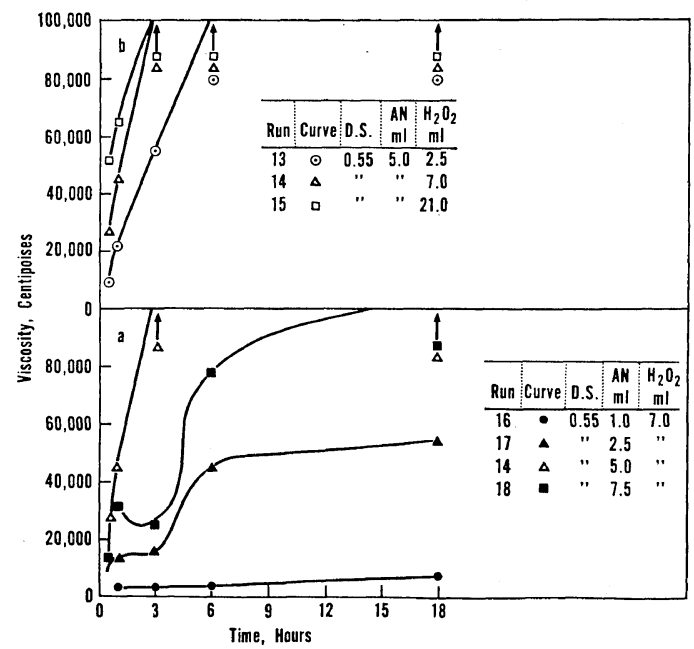

Figure 3. Viscosity development in 0.55 D. S. starch xanthate-hydrogen peroxide-acrylonitrile reactions. The arrow sign signifies that at this time point the viscosity was somewhere in excess of 100,000 centipoises, which is the maximum viscosity that the instrument used could measure.

on the exact $\mathrm{AN}$ and $\mathrm{H}_{2} \mathrm{O}_{2}$ amounts as shown by Run 7 in the series Runs 1, 7, 13 of Figures 1b, 2b, and $3 \mathrm{~b}$ (but compare with the series Runs 2, 8, 14 and 3, 9, 15), and Run 12 in the series Runs 6, 12, 18 of Figures 1a, 2a, and 3a (but compare with the series Runs 5,11,17). Very small amounts of AN $(1.0-2.5 \mathrm{ml})$ are not sufflcient to produce notable viscosity increases with 0.23 D.S. (intermediate) xanthate or less. These data suggest that there is an intimate relationship in the magnitude of D.S., amount of $\mathrm{AN}$, and amount of $\mathrm{H}_{2} \mathrm{O}_{2}$ for maximum viscosity development in this reaction. These phenomena signify that possibly several reactions are involved: cyanoethylation of xanthate group, cyanoethylation of hydroxyl group, graft polymerization, homopolymerization, and crosslinking. Dimov and Pavlov ${ }^{12}$ noted some of these possibilities in their first study of the system reaction with precipitated cellulose xanthate, heterogeneously in aqueous ethanol over an alkaline to acidic $\mathrm{pH}$ range.

The analytical data (see Table I) illustrate further the complexity of the reactions in connection with the relationship between ingredients, as others have also concluded..$^{13,14}$ For example, use of $5-\mathrm{m} l$ AN and $7-\mathrm{ml} \mathrm{H}_{2} \mathrm{O}_{2}$ mixture results in retention in the 


\section{G. G. MAHER}

Table I. Effect of D. S., ${ }^{\text {a }}$ AN, and hydrogen peroxide levels in SX-AN graft reaction

\begin{tabular}{|c|c|c|c|c|c|c|c|c|c|c|}
\hline \multirow{3}{*}{ Run No. } & \multicolumn{5}{|c|}{ Reaction mixture ingredients } & \multirow{3}{*}{$\mathrm{pH}_{18 \mathrm{~h}}$} & \multicolumn{4}{|c|}{$\begin{array}{c}\text { Analyses of cross-linked } \\
\text { starch-PAN graft product, } 18 \mathrm{~h}\end{array}$} \\
\hline & \multicolumn{3}{|c|}{ Initial } & \multicolumn{2}{|c|}{ Volume, $\mathrm{m} l$} & & \multirow{2}{*}{$\begin{array}{l}\text { Elements } \\
\text { found, } \%\end{array}$} & \multicolumn{3}{|c|}{ Calculated for graft composition } \\
\hline & $\begin{array}{l}\text { Xanthate } \\
\text { D.S. }\end{array}$ & $\begin{array}{l}\text { Xanthate } \\
\text { wt, } g^{b}\end{array}$ & $\begin{array}{l}\text { Starch } \\
\text { wt, g }\end{array}$ & $\mathrm{AN}^{\mathrm{c}}$ & $\begin{array}{l}30-\% \\
\mathrm{H}_{2} \mathrm{O}_{2}\end{array}$ & & & Elements, $_{\%}^{\mathrm{d}}$ & $\begin{array}{c}\text { Xanthate } \\
\text { D.S. }\end{array}$ & $\begin{array}{c}\mathrm{AN}^{\mathrm{e}} \text { added, } \\
\%\end{array}$ \\
\hline 1 & $0.14^{\mathrm{f}}$ & 1.467 & 1.353 & 5.0 & 2.5 & & $\begin{array}{c}17.04, \mathrm{~N} \\
1.02, \mathrm{~S}\end{array}$ & $\begin{array}{c}17.06, \mathrm{~N} \\
1.08, \mathrm{~S}\end{array}$ & 0.08 & 64 \\
\hline 2 & & & & 5.0 & 7.0 & 3.1 & $\begin{array}{c}14.96, \mathrm{~N} \\
1.37, \mathrm{~S}\end{array}$ & $\begin{array}{c}14.95, \mathrm{~N} \\
1.32, \mathrm{~S}\end{array}$ & 0.08 & 46 \\
\hline 3 & & & & 5.0 & 21.0 & & & & & \\
\hline 4 & & & & 1.0 & 7.0 & $3.1^{\mathrm{g}}$ & & & & \\
\hline 5 & & & & 2.5 & 7.0 & 3.1 & & & & \\
\hline 6 & & & & 7.5 & 7.0 & 3.1 & $\begin{array}{c}15.04, \mathrm{~N} \\
0.63, \mathrm{~S}\end{array}$ & $\begin{array}{c}15.04, \mathrm{~N} \\
0.66, \mathrm{~S}\end{array}$ & 0.04 & 31 \\
\hline 7 & $0.23^{\mathrm{h}}$ & 1.755 & 1.541 & 5.0 & 2.5 & $2.5^{\mathrm{i}}$ & $\begin{array}{c}15.34, \mathrm{~N} \\
1.44, \mathrm{~S}\end{array}$ & $\begin{array}{c}15.35, \mathrm{~N} \\
1.43, \mathrm{~S}\end{array}$ & 0.09 & 56 \\
\hline 8 & & & & 5.0 & 7.0 & 2.2 & $\begin{array}{c}17.07, \mathrm{~N} \\
1.22, \mathrm{~S}\end{array}$ & $\begin{array}{c}17.01, \mathrm{~N} \\
1.21, \mathrm{~S}\end{array}$ & 0.09 & 73 \\
\hline 9 & & & & 5.0 & 21.0 & 2.0 & $\begin{array}{c}16.77, \mathrm{~N} \\
1.08, \mathrm{~S}\end{array}$ & $\begin{array}{c}16.70, \mathrm{~N} \\
1.12, \mathrm{~S}\end{array}$ & 0.08 & 69 \\
\hline 10 & & & & 1.0 & 7.0 & $2.2^{\mathrm{j}}$ & & & & \\
\hline 11 & & & & 2.5 & 7.0 & 2.2 & $\begin{array}{c}14.62, \mathrm{~N} \\
0.73, \mathrm{~S}\end{array}$ & $\begin{array}{c}14.62, \mathrm{~N} \\
0.69, \mathrm{~S}\end{array}$ & 0.04 & 98 \\
\hline 12 & & & & 7.5 & 7.0 & 2.2 & $\begin{array}{c}17.32, \mathrm{~N} \\
1.14, \mathrm{~S}\end{array}$ & $\begin{array}{c}17.41, \mathrm{~N} \\
1.16, \mathrm{~S}\end{array}$ & 0.09 & 52 \\
\hline $12 \mathrm{a}$ & 0.26 & 1.640 & 1.405 & 5.0 & 7.0 & $<6^{\mathrm{k}}$ & $\begin{array}{c}17.97, \mathrm{~N} \\
0.90, \mathrm{~S}\end{array}$ & $\begin{array}{c}17.81, \mathrm{~N} \\
0.87, \mathrm{~S}\end{array}$ & 0.07 & 77 \\
\hline $12 b$ & & & & & & $<6$ & $\begin{array}{c}17.61, \mathrm{~N} \\
0.88, \mathrm{~S}\end{array}$ & $\begin{array}{c}17.67, \mathrm{~N} \\
0.89, \mathrm{~S}\end{array}$ & 0.07 & 75 \\
\hline 13 & $0.55^{1}$ & 1.886 & 1.415 & 5.0 & 2.5 & $2.4^{\mathrm{m}}$ & & & & \\
\hline 14 & & & & 5.0 & 7.0 & 2.1 & $\begin{array}{c}13.67, \mathrm{~N} \\
4.13, \mathrm{~S}\end{array}$ & $\begin{array}{c}13.61, \mathrm{~N} \\
4.13, \mathrm{~S}\end{array}$ & 0.24 & 42 \\
\hline 15 & & & & 5.0 & 21.0 & 1.7 & $\begin{array}{c}14.36, \mathrm{~N} \\
3.68, \mathrm{~S}\end{array}$ & $\begin{array}{c}14.37, \mathrm{~N} \\
3.73, \mathrm{~S}\end{array}$ & 0.23 & 47 \\
\hline 16 & & & & 1.0 & 7.0 & $2.1^{\mathrm{n}}$ & & & & \\
\hline 17 & & & & 2.5 & 7.0 & 2.1 & & & & \\
\hline 18 & & & & 7.5 & 7.0 & 2.1 & $\begin{array}{c}13.83, \mathrm{~N} \\
2.14, \mathrm{~S}\end{array}$ & $\begin{array}{c}13.71, \mathrm{~N} \\
2.15, \mathrm{~S}\end{array}$ & 0.12 & 27 \\
\hline
\end{tabular}

a Abbreviations: D. S., degree of substitution; AN, acrylonitrile; SX, starch xanthate; PAN, polyacrylonitrile.

${ }^{b}$ As sodium starch xanthate (NaSX).

c Five milliliters weigh $3.985 \mathrm{~g}$.

d Elements: N, nitrogen; $\mathrm{S}$, sulfur.

e Given as percent of the AN in the reaction mixture, column 5 .

f See Figure 2 for viscosity development.

g The pH was 3.2 in each of Runs 4, 5, and 6 after $1 \mathrm{~h}$ of reaction.

${ }^{\text {h }}$ See Figure 3 for viscosity development.

${ }_{1}$ The pH was 2.8 in Run 7, 2.4 in Run 8, and 2.0 in Run 9 after $3 \mathrm{~h}$ of reaction.

$j$ The $\mathrm{pH}$ was 2.5 in each of Runs 10, 11, and 12 after $1 \mathrm{~h}$ of reaction.

The $\mathrm{pH}$ was 2.4 in each of Runs 10, 11, and 12 after $4 \mathrm{~h}$ of reaction.

${ }^{\mathrm{r}}$ The $\mathrm{pH}$ of the xanthate solution in Run 12a was adjusted to 6.0 prior to $\mathrm{AN}-\mathrm{H}_{2} \mathrm{O}_{2}$ addition.

The $\mathrm{pH}$ of the xanthate solution in Run $12 \mathrm{~b}$ was adjusted to 2.0 prior to $\mathrm{AN}-\mathrm{H}_{2} \mathrm{O}_{2}$ addition.

Final pH by indicator paper was less than 6 in both cases.

1 See Figure 4 for viscosity development.

$m$ The $\mathrm{pH}$ was 2.7 in Run 13, 2.4 in Run 14, and 2.0 in Run 15 after $1 \mathrm{~h}$ of reaction.

The $\mathrm{pH}$ was 2.7 in Run 13, 2.3 in Run 14, and 1.7 in Run 15 after $3 \mathrm{~h}$ of reaction.

$n$ The $\mathrm{pH}$ was 2.5 in each of Runs 16,17 , and 18 after $1 \mathrm{~h}$ of reaction. 
precipitated product of 46 to 73 to $42 \%$ of the AN, as the xanthate D.S. progresses from 0.14 to 0.23 to 0.55. Yet for 0.23 D.S. xanthate and $7-\mathrm{ml} \mathrm{H}_{2} \mathrm{O}_{2}$ the progressive increase of $\mathrm{AN}$ from 2.5 to 5.0 to $7.5 \mathrm{~m} l$ results in a progressive decrease, 98 to 73 to $52 \%$, in the polymerization of the AN. Other patterns can be picked out in the data in Table I. With 0.23 D.S. xanthate, Run 11, which had a barely noticeable viscosity development, still yielded a solid whose nitrogen content indicated a 98-\% conversion of the AN used. Effervescence occurs, but no viscous or turbid gels form with 0.04 D. S. xanthate and 5-m $l \mathrm{AN}$ and $7-\mathrm{m} l \mathrm{H}_{2} \mathrm{O}_{2}$; but the $\mathrm{pH}$ drops only to 6.8 , whereas $0.09,0.10$, and 0.14 D.S. xanthates yield 4.7, 3.3, and $3.1 \mathrm{pH}$, respectively, in gels with $>10,000-\mathrm{cP}$ viscosity.

The yields were $95-100 \%$ for materials of the calculated compositions. At longer reaction times, Dimov and Pavlov ${ }^{13}$ found maximum grafting at $\mathrm{pH} \mathrm{3}$, in keeping with our maximum yields at final $\mathrm{pH}$ 2.5-3.1, but Hornof, et al., favor alkaline $\mathrm{pH}$ levels for maximum grafting. ${ }^{14}$ In their report on the cellulose xanthate reaction in a heterogeneous, completely aqueous, constant 1.54 pH media, Dimov and Pavlov ${ }^{13}$ found that increasing $\mathrm{H}_{2} \mathrm{O}_{2}$ beyond a certain point resulted in decreasing AN polymerization, and we agree; but again one gets a different impression from Hornof, et al. ${ }^{14}$ Contrary to Dimov and Pavlov's findings, we determined that decreasing D.S. in the xanthate does not necessarily mean that a drop in percent polymerization of added AN will occur.

Dimov and Pavlov did not give any analytical data on sulfur in their products or state its absence; thus more exacting comparisons of the works are difficult. However, in the free-radical grafting reaction mechanism which they have proposed (seemingly appropriate from the data they presented) the xanthate group is completely eliminated as $\mathrm{CS}_{2}$. Yamaguchi, et al., found a considerable sulfur content in some of their vinyl compound grafts onto monomeric xanthates, but unfortunately they gave no information on products containing AN polymerized by their proposed anionic initiation. Likewise, Shasha, et al., have no analytical data on a brief polymerization involving acrylamide. ${ }^{4}$ Possibly these works ${ }^{4,5}$ indicate that a reaction mechanism without loss of xanthate groups is operative in the vinyl com- pound polymerization. In our reaction system, one might consider that the developing acidity could account for some xanthate-group losses by hydrolysis, but since we start at such a high $\mathrm{pH}$ (11) such a loss would seem minimal as other reactions would begin before the $\mathrm{pH}$ drops to the acidic level needed to effect such hydrolyses. ${ }^{4} \quad$ Hydrolyses to remove the xanthate group from SX and leave the starch free would not account for gelation since, at the $2-\%$ level we have used, starch does not form gels of the rapid viscosity-development magnitude we obtained. ${ }^{15}$ It must be emphasized that the homogeneous and highly alkaline system of our experimentation is a big departure from the nature of the systems previous workers have used most, namely a heterogeneous, acidic $\mathrm{pH}$, and sometimes buffered one. The analyses of Table I for products precipitated from the reaction media after $18 \mathrm{~h}$ indicate that xanthate groups may remain at $17-57 \%$ of the original D.S. of the SX used, depending on the D.S. and $\mathrm{AN}-\mathrm{H}_{2} \mathrm{O}_{2}$ relationship that existed at the start.

Actually, it is believed that the xanthate group no longer exists per se, but that oxidation by peroxide has resulted in formation of bis(alkoxythiocarbonyl)disulfide, according to the following reaction 1 .

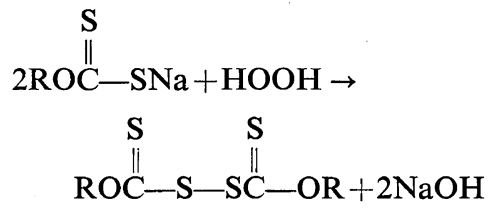

Previous studies with model monomeric compounds strongly support this contention, ${ }^{4}$ showing that the oxidation reaction was minimal when the xanthate concentration was $c a .1 \%$ as opposed to $10 \%$; and this paper, we have used $1.5-2.0-\%$ SX concentrations as the average in our system. Nevertheless, it is felt that this oxidative reaction is the one that takes place and accounts for the cross-linked nature of the grafted product, especially in the case of a PAN graft. The higher the D. S. in the starting SX, the more crosslinks will be formed, and in Table I, one notes that the calculated residual xanthate-group expression for the products varies directly with the original xanthate D. S. In the foregoing reaction equation, $\mathrm{R}$ represents the anhydroglucosyl unit as being the presentation of the starch molecule: 


\section{G. G. MAHER}

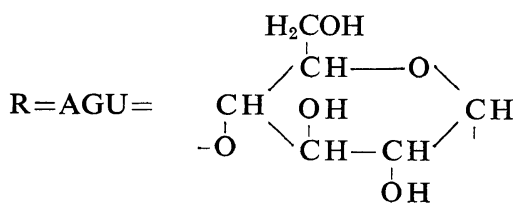

It is to be understood that in the SX molecule, the xanthate group can be distributed on any of the three hydroxyl groups of the unit in patterns that have been elucidated. ${ }^{16}$ Consequently, the reactions of the xanthate groups may be distributed between reaction 1 given above and any of the other reactions which follow. It is possible that the xanthate groups, distributed on any one AGU, could take part in more than one reaction.

None of the above researchers mentioned effervescence or a self-acidifying phenomenon until Hornof, et al., noted a small pH drop. ${ }^{14}$ This phenomenon stems from a known reaction of $\mathrm{H}_{2} \mathrm{O}_{2}$ in alkaline solution that removes sulfur from a number of classes of sulfurous compounds. ${ }^{17}$ When projected to the situation where a minimal amount of alkali exists, the reaction is as described by eq 2 .

$$
\begin{aligned}
& \mathrm{ROCSSNa}+8 \mathrm{H}_{2} \mathrm{O}_{2}+\mathrm{NaOH} \rightarrow \\
& 2 \mathrm{H}_{2} \mathrm{SO}_{4}+\mathrm{Na}_{2} \mathrm{CO}_{3}+\mathrm{ROH}+6 \mathrm{H}_{2} \mathrm{O}
\end{aligned}
$$

The acid and carbonate give rise to the gas, $\mathrm{CO}_{2}$, and a remaining mole of acid to account for the effervescence and $\mathrm{pH}$ drop. In the crosslinking reaction, $1.2 \mathrm{~mol}$ of alkali are generated per cross- link formed. This alkali would be available for the gas forming reaction, of course, and is an important element to consider in connection with the previously made statement concerning viscosity development, namely that there is an intimate proper relationship between the SX D. S. and the amounts of $\mathrm{H}_{2} \mathrm{O}_{2}$ and vinyl monomer to use.

During the foregoing reaction the formation of the free radical, $\mathrm{RO} \cdot$, as has been postulated ${ }^{13,18}$ in place of $\mathrm{ROH}$, permits the grafting reaction 3 .

$$
\begin{aligned}
& \mathrm{RO} \cdot+(n+1) \mathrm{CH}_{2}=\mathrm{CHR}^{\prime} \rightarrow \\
& \mathrm{RO}\left(\mathrm{CH}_{2} \mathrm{CHR}^{\prime}\right)_{n} \mathrm{CH}_{2} \mathrm{CH}_{2} \mathrm{R}^{\prime}
\end{aligned}
$$

With the proper balance of reactants, then, the sum of reactions 2 and 3 becomes 4 for the system.

$$
\begin{aligned}
& \mathrm{ROCSSNa}+\mathrm{NaOH}+8 \mathrm{H}_{2} \mathrm{O}_{2}+(n+1) \mathrm{CH}_{2}= \\
& \mathrm{CHR}^{\prime} \rightarrow \mathrm{RO}\left(\mathrm{CH}_{2} \mathrm{CHR}\right)_{n} \mathrm{CH}_{2} \mathrm{CH}_{2} \mathrm{R}^{\prime} \\
& +\mathrm{Na}_{2} \mathrm{SO}_{4}+7 \mathrm{H}_{2} \mathrm{O}+\mathrm{H}_{2} \mathrm{SO}_{4}+\mathrm{CO}_{2} \uparrow
\end{aligned}
$$

Thus, to accommodate the existence of the crosslinking through xanthate oxidation reaction 1 is added to 4 to give the overall 5 .

$$
\begin{aligned}
& 5 \mathrm{ROCSSNa}+\mathrm{NaOH}+25 \mathrm{H}_{2} \mathrm{O}_{2} \\
& +3(n+1) \mathrm{CH}_{2}=\mathrm{CHR}{ }^{\prime} \rightarrow 3 \mathrm{RO}\left(\mathrm{CH}_{2} \mathrm{CHR}^{\prime}\right)_{n} \\
& \mathrm{CH}_{2} \mathrm{CH}_{2} \mathrm{R}^{\prime}+\mathrm{ROCSSSSCOR}+3 \mathrm{Na}_{2} \mathrm{SO}_{4} \\
& +3 \mathrm{H}_{2} \mathrm{SO}_{4}+21 \mathrm{H}_{2} \mathrm{O}+3 \mathrm{CO}_{2} \uparrow
\end{aligned}
$$

This final reaction reflects the predominance of the grafting reaction over crosslinking, in keeping with the analytical findings, and the product can be visualized as

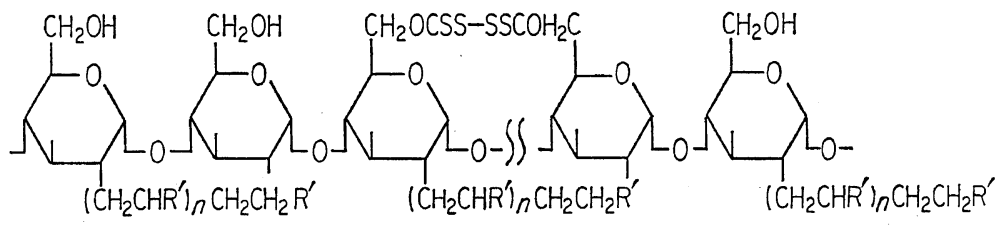

to show two cross-linked, grafted starch xanthide molecule chains.

Several mixtures of compounds were studied to see what reactions extraneous to grafting polymerizations might occur under our general conditions. Over 24-h periods, $\mathrm{AN}$ and $\mathrm{H}_{2} \mathrm{O}_{2}$ showed no signs of reaction at $\mathrm{pH} 2-6$. Appropriate mixtures of $\mathrm{CS}_{2}, \mathrm{AN}, \mathrm{H}_{2} \mathrm{O}_{2}$, and $\mathrm{NaOH}$ dropped from $\mathrm{pH} 10$ to $\mathrm{pH} 6.5$ with no other sign of reaction. This $\mathrm{pH}$ drop is consistent with the formation of $2 \mathrm{NaHSO}_{3}$ and $\mathrm{NaHCO}_{3}$ from peroxide oxidation of any free $\mathrm{CS}_{2}$ that might be present in the system. There were color loss and slight turbidity development but no heating, gas evolution, or precipitation in either xanthate and $\mathrm{AN}$ or xanthate and $\mathrm{H}_{2} \mathrm{O}_{2}$ mixtures, although the $\mathrm{pH}$ in the latter fell to 2.63.8 within the first hour, correlating indirectly with the xanthate D. S. These pH levels are consistent with an oxidative pathway of peroxide, without excess alkali present, on a xanthate as per eq 6.

$$
\begin{aligned}
& \mathrm{ROCSSNa}+4 \mathrm{H}_{2} \mathrm{O}_{2} \rightarrow \mathrm{ROCSOH} \\
& +\mathrm{NaHSO}_{4}+3 \mathrm{H}_{2} \mathrm{O}
\end{aligned}
$$


Since there is an excess alkali present, this possible side reaction is discounted. These observations broaden those of Dimov and Pavlov and provide a stronger base for eliminating possible side reactions to the main reaction of AN graft polymerization initiated by xanthated polysaccharide and leave reaction 5 as sole portrayal of our system. It is possible though that the mechanism of grafting could be considered as an anionic polymerization since we have used water as the solvent, which has a higher dielectric constant than any of the organic solvents which Yamaguchi, et al., used. Their results indicated that in an anionic mechanism consideration for AN grafting, the higher the dielectric constant of the solvent was, the higher were the rate of initiation and propagation and yield of graft copolymer.

\section{Reaction with Other Vinyl Monomers}

In working with monomers other than AN, some qualitative differences were noted. With acrolein the color loss, effervescence, and heating were nearly instantaneous with mixing, and in a minute or two the beaker was too hot to hold. The gas evolution was the most profuse, yet the bubbles had difficulty in escaping because a gel for- med so quickly. The gel was a compromise between translucency and opaqueness due to small, white globules ( $<1 \mathrm{~mm}$ diameter) which increased with time. Acrylic acid likewise gave nearly instantaneous color loss and effervescence, but no heat evolution. It produced an easily worked precipitate in ethanol; but acrylamide, whose reaction character paralleled that of $\mathrm{AN}$, formed a gummy, ropy, hard-to-work mass in ethanol. Acrylamide produced more gas, but methyl acrylate less gas, than AN. Also, the color loss and warming were more gradual with acrylate than with AN. Styrene reacted slowly, even though being stirred, and took about $30 \mathrm{~min}$ to give a noticeable color fading and white opaque appearance due to fine particle formation and suspension. The induction period with styrene lessened with increasing $\mathrm{H}_{2} \mathrm{O}_{2}$ amounts and there was a barely detectable warming; but there was no effervescence or gel formation, even during the extended reaction time producing a heavily opaque suspension that gave a sediment only upon centrifuging. However, the addition of an emulsifying agent such as Tween 85 to the reaction mixture with styrene hastened the reaction. If no water other than that in the xanthate preparation

Table II. SX ${ }^{a}$ graft reaction with various vinyl monomers and hydrogen peroxide

\begin{tabular}{|c|c|c|c|c|c|c|c|c|c|}
\hline \multicolumn{6}{|c|}{ Reaction mixture ingredients } & \multirow{3}{*}{$\begin{array}{c}\text { Viscosity, } \\
\text { after } \\
0.5-1 \mathrm{~h} \\
\mathrm{cP}\end{array}$} & \multirow{2}{*}{\multicolumn{3}{|c|}{$\frac{\begin{array}{c}\text { Analyses of starch }-\mathrm{PVM} \text { graft } \\
\text { product } 18 \mathrm{~h}^{\mathrm{a}}\end{array}}{\begin{array}{c}\text { Calculated for graft } \\
\text { composition }\end{array}}$}} \\
\hline \multicolumn{3}{|c|}{ Initial } & \multicolumn{2}{|c|}{$\begin{array}{c}\text { Vinyl } \\
\text { monomer }^{\mathrm{a}}\end{array}$} & \multirow{2}{*}{$\begin{array}{c}\text { Vol. of } \\
30-\% \\
\mathrm{H}_{2} \mathrm{O}_{2} \text {, } \\
\mathrm{m} l\end{array}$} & & & & \\
\hline $\begin{array}{l}\text { Xanthate } \\
\text { D.S. }{ }^{\mathrm{b}}\end{array}$ & $\begin{array}{l}\text { Xanthate } \\
\text { wt, } g^{\mathrm{b}}\end{array}$ & $\begin{array}{l}\text { Starch } \\
\text { wt, g }\end{array}$ & Name & wt, $\mathrm{g}$ & & & $\begin{array}{l}\text { Elements } \\
\text { found, \% }\end{array}$ & $\underset{\%}{\text { Elements }^{c}}$ & $\begin{array}{l}\text { Monomer }^{\mathrm{d}} \\
\text { added, \% }\end{array}$ \\
\hline 0.20 & 0.888 & 0.794 & $\mathrm{AM}$ & 2.50 & 7.0 & $35,000^{\mathrm{e}}$ & $\begin{array}{r}12.99, \mathrm{~N} \\
46.89, \mathrm{C} \\
7.44, \mathrm{H}\end{array}$ & $\begin{array}{r}13.03 \mathrm{~N} \\
46.97, \mathrm{C} \\
7.40, \mathrm{H}\end{array}$ & 69.5 \\
\hline 0.20 & 0.888 & 0.794 & $\mathrm{AA}$ & 2.65 & 7.0 & $>100,000^{f}$ & $\begin{array}{r}0.00, \mathrm{~S} \\
43.85, \mathrm{C} \\
5.53, \mathrm{H}\end{array}$ & $\begin{array}{r}0.00, \mathrm{~S} \\
43.96, \mathrm{C} \\
5.58, \mathrm{H}\end{array}$ & 50.0 \\
\hline 0.10 & 1.749 & 1.650 & MA & 6.28 & 7.0 & $22,000^{\mathrm{g}}$ & & & \\
\hline 0.10 & 1.749 & 1.650 & $\mathrm{AC}$ & 4.21 & 7.0 & $2,500^{\mathrm{h}}$ & & & \\
\hline
\end{tabular}

a Abbreviations: SX, starch xanthate; D. S., degree of substitution; AM, acrylamide; AA, acrylic acid; MA, methylacrylate; AC, acrolein; PVM, poly(vinyl monomer).

b As sodium starch xanthate (NaSX).

c $\mathrm{C}$, carbon; $\mathrm{H}$, hydrogen; $\mathrm{N}$, nitrogen; $\mathrm{S}$, sulfur.

d Given as percent of the monomer in the reaction mixture, columns 4 and 5 .

e The same at $18 \mathrm{~h}$; opaque and flowable gel.

f The same at $18 \mathrm{~h}$; opaque and nonflowable gel.

g An opaque, nonflowable gel, pH 3.9.

h A translucent, flowable gel; at $18 \mathrm{~h}$, an opaque, flowable gel, 12,000-cP viscosity, $\mathrm{pH} 3.0$. 
was used, the reaction was as rapid as with $\mathrm{AN}$, much heat was generated, and a nonflowable gel formed. Gas evolution was hard to assess because the solids rapidly formed balls which were not processed further; but it may be noted that the ratio of styrene to starch xanthate was in the same range as the styrene to cellulose xanthate ratio that Kokta and Valade found to be best for grafting styrene to cellulose. ${ }^{18}$ Table II gives data on some of the preparations with these monomers. The percent of monomer polymerized seems consistent with findings with AN.

\section{Infrared Spectra Interpretations}

The IR (Figure 4) of precipitated, cross-linked starch-graft copolymers show very clearly the nitrile absorption band at $2260 \mathrm{~cm}^{-1}$ of the AN copolymer, the carboxyl absorption band at 1730 $\mathrm{cm}^{-1}$ and the carboxylate ion absorption band at $1570 \mathrm{~cm}^{-1}$ of the AA copolymer, the broad combination of amide group bands and water absorption band over the range of $1600-1690 \mathrm{~cm}^{-1}$ of the $\mathrm{AM}$ copolymer, and the starch constitutive group absorption bands at $3333-3448 \mathrm{~cm}^{-1}$ and in the range of $833-1176 \mathrm{~cm}^{-1}$ in all of the copolymers.

Unfortunately, absorptions by the starch are so strong and located at such wave numbers that they mask any absorptions one might expect to see due to the existence of the xanthide crosslink. In fact, absorptions that have been attributed to the xanthate group at $c a .1200,1000,920$, and 850 $\mathrm{cm}^{1.5}$ cannot be seen in IR of SX with an original D.S. as high as 0.60 . Therefore, the IR have not been of value to establish the presence of xanthide crosslinking in the products. In the case of poly- meric grafted side chains of AN on various polymeric backbone molecules, a number of investigations have been reported on the development of color and gelation induced by alkali or heat or irradiation on the graft copolymers and a mechanism for the formation of crosslinks through the PAN side chain grafts has been proposed. ${ }^{19}$ The $-\mathrm{C}=\mathrm{N}-$ and the $-\mathrm{C}=\mathrm{N}-\mathrm{C}=\mathrm{N}-$ bondings present therein account for infrared adsorptions at $1660 \mathrm{~cm}^{-1}$ and $1590 \mathrm{~cm}^{-1}$ which are questionable in appearance in our spectrum of graft copolymer, curve 1, Figure 4 due to the strong absorption by very difficultly removed, absorbed water of starch products at that wave number area. ${ }^{20}$ Therefore, we are left with the formation of gels as the indicator of crosslink establishment and many investigators consider gelation as a very strong evidence for crosslinking. Of course, poly(acrylic acid) and poly(acrylamide) are such strong hydrogenbond crosslink formers that graft copolymers with them in the side chains would need no other structures or mechanisms stemming from the backbone polymer to account for crosslinking and gelation. $^{21}$

The composition by weight in the starch-PAN product, assuming all polymerized $\mathrm{AN}$ is in the form of a graft, is $c a$. 2:1 PAN: starch. This product did not dissolve in dimethyl sulfoxide (DMSO) $(0.05 \mathrm{~g}$ of 60 -mesh powder per $5 \mathrm{ml})$ or in dimethyl formamide (DMF) on standing 1 week at room temperature or upon heating at $100^{\circ} \mathrm{C}$ for $15 \mathrm{~min}$, but it did acquire a gelatinous appearance on the particle surfaces. According to Brockway and Seaberg, ${ }^{10}$ this solution behavior is indicative of crosslinking in such a starch

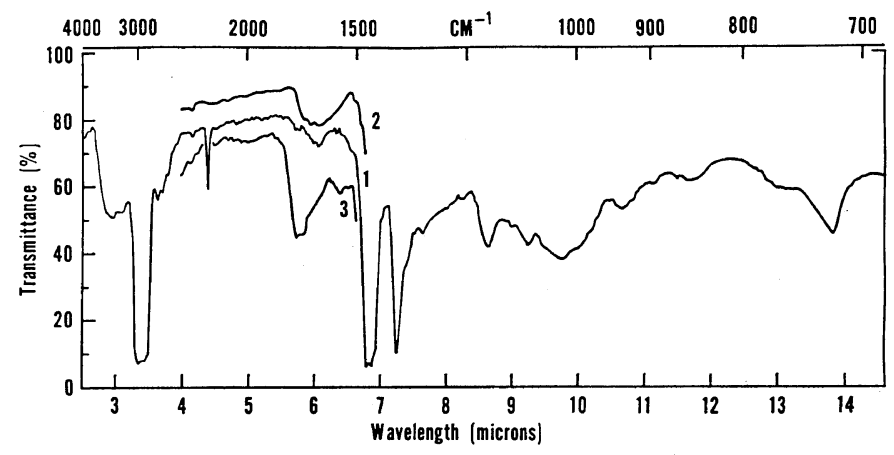

Figure 4. Infrared spectra of graft copolymers from starch xanthate-hydrogen peroxidevinyl monomer reactions. 
copolymer derivative. In contrast, SX of 0.13 $0.51 \mathrm{D}$. S. was found to be readily soluble in roomtemperature DMSO, but insoluble in even hot DMF in our test. There seems to be a hint of carbonyl absorption at $1730 \mathrm{~cm}^{-1}$ in the IR shown in Figure 4 for the starch-PAN, suggesting that some hydrolysis of nitrile group has ensued possibly. Such hydrolysis would not be expected to alter the solubility character of and deductions for composition and structure in the graft copolymers, since like $\mathrm{PAN}^{10}$ polyacrylamide $(500,000 \mathrm{~mol}$ wt; chemical No. 8249, Polysciences, Inc., Warren, Pennsylvania) is completely soluble in warm DMSO, but only slightly soluble in DMF in our test. Poly(acrylic acid) $(250,000 \mathrm{~mol} \mathrm{wt}$; chemical No. 3112, Polysciences, Inc.) is completely soluble in DMSO and in DMF at room temperature in our test. Poly(acrylic acid) and polyacrylamide are both completely soluble in ethanol: water $2: 1$, as we have also found, and hence if formed as homopolymers in our system, they would not appear in the solid graft copolymers isolated by the insolubilization in ethyl alcohol technique.

The amount of DMF extract obtained from the cross-linked starch-PAN product, which was carried out to find any homopolymers, was meager. The IR spectra of the product, the extract, and the residue left after extraction, all had the same numerical ratio of nitrile group absorption to starch absorption at the $2.9-$ and $8.5-\mu \mathrm{m}$ points. This equality indicates a negligible amount of any homopolymer formation of PAN and a possible high degree of uniformity in the PAN-starch. Dimov and Pavlov found little $(<20 \%)$ homopolymer formation occurring at $c a .3 \mathrm{pH},{ }^{13}$ and Hornof, et al., found that alkaline $\mathrm{pH}$ and large amounts of $\mathrm{H}_{2} \mathrm{O}_{2}$ eliminated homopolymer formation almost completely. ${ }^{14}$ Since the grafting reaction we have used here encompasses those factor limits and ranges, the grafting method with gelatinized starch in the alkaline, soluble form may offer advantages in uniformity of products over those produced in a heterogeneous system of substrate.

A patent has been issued concerning the utility of the process reaction and product in foam-rubber preparation. $^{22}$

Acknowledgments. W.R. Hensley, L.D. Miller, and W. L. Williams prepared the starch xanthates.
B. R. Heaton, K. A. Jones, C. E. McGrew, and I. M. Schulte performed elemental analyses.

The mention of firm names or trade products does not imply that they are endorsed or recommended by the U.S. Department of Agriculture over other firms or similar products not mentioned.

\section{REFERENCES}

1. V. Hornof, B. V. Kokta, and J. L. Valade, $J$. Appl. Polym. Sci., 20, 1543 (1976).

2. R. W. Faessinger and J. S. Conte (to Scott Paper Co.), U.S. Patent 3, 359, 224 (December 19, 1967).

3. D. Trimnell, E. I. Stout, W. M. Doane, and C. R. Russell, J. Appl. Polym. Sci., 21, 655 (1977).

4. B. S. Shasha, W. M. Doane, and C. R. Russell, Carbohydr. Res., 18, 251 (1971).

5. K. Yamaguchi, O. Sonoda, and Y. Minoura, $J$. Polym. Sci., Part A-1, 10, 63 (1972).

6. C. L. Swanson, T. R. Naffziger, C. R. Russell, B. T. Hofreiter, and C. E. Rist, Ind. Eng. Chem., Prod. Res. Dev., 3, 22 (1964).

7. C. R. Russell, R. A. Buchanan, C. E. Rist, B. T. Hofreiter, and A. J. Ernst, TAPPI, 45, 557 (1962).

8. E. B. Lancaster, L. T. Black, H. F. Conway, and E. L. Griffin, Jr., Ind. Eng. Chem., Prod. Res. Dev., 5, 354 (1966).

9. D. C. White, Mikrochim. Acta, 807 (1962).

10. C. E. Brockway and P. A. Seaberg, J. Polym. Sci., Part A-1, 5, 1313 (1967).

11. G. G. Maher, J. A. Douglas, C. R. Russell, and C. E. Rist, J. Polym. Sci., Part A-1, 8, 1637 (1970).

12. K. Dimov and P. Pavlov, Papier, 23, 809 (1969).

13. K. Dimov and P. Pavlov, J. Polym. Sci., Part A-1, 7, 2775 (1969).

14. V. Hornof, B. V. Kokta, and J. L. Valade, J. Appl. Polym. Sci., 19, 545 (1975).

15. R. J. Smith, "Starch: Chemistry \& Technology, Industrial Aspects," R. L. Whistler and E. F. Paschall, Ed., Academic Press, Inc., New York, N. Y., 1967, Vol. II, p. 598.

16. W. M. Doane, C. R. Russell, and C. E. Rist, Staerke, 17, 77 (1965).

17. R. Kitamura, J. Pharm. Soc. Jpn., 57, 5, 29, 51, 233, 893 (1937).

18. B. V. Kokta and J. L. Valade, TAPPI, 55, 366 (1972).

19. M. S. Joshi, J. Silverman, and K. Singer, $J$. Polym. Sci., Polym. Lett. Ed., 14, 723 (1976).

20. J. R. van der Bij and W. F. Vogel, Staerke, 14, 


\section{G. G. MAHER}

113 (1962).

21. E. Gruber, J. Mohammed, S. Allonsh, and J. Schurz, Cellulose Chem. Technol., 10, 577 (1976).
22. G. G. Maher, U. S. Patent No. 4,005,040, January $25,1977$. 